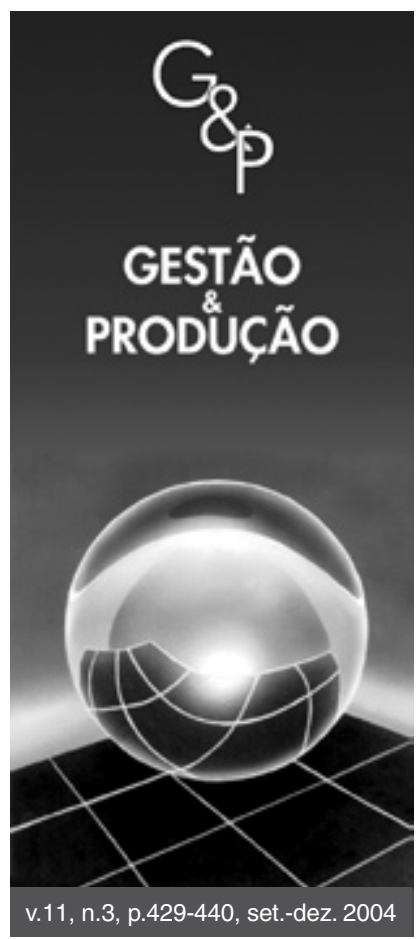

\title{
DESENVOLVIMENTO DE UMA FERRAMENTA PARA A GESTÃO DA LOGÍSTICA DA CAPTAÇÃO DE LEITE DE UMA COOPERATIVA AGROPECUÁRIA
}

\author{
Ricardo Silveira Martins \\ Débora Silva Lobo \\ Weimar Freire da Rocha Júnior \\ Homero Fernandes de Oliveira
}

Grupo de Pesquisas em Transportes, Logística e Modelagem de Sistemas. Universidade Estadual do Oeste do Paraná (Unioeste),

C.P. 520, CEP 85900-970 Toledo - PR, Brasil, e-mail: ricleimartins@uol.com.br, dslobo@uol.com.br, wrocha@unioeste.br, sistemas@fasul.com.br

\section{Paulo do Carmo Martins Luiz Carlos Takao Yamaguchi}

Embrapa Gado de Leite, Rua Eugênio do Nascimento, 610, Dom Bosco, CEP 36038-330, Juiz de Fora - MG, Brasil e-mail: takao@cnpgl.embrapa.br, pmartins@ cnpgl.embrapa.br

Recebido em 14/5/2004

Aceito em 22/10/2004

\section{Resumo}

O objetivo geral deste artigo é apresentar o desenvolvimento e implementação da racionalização da gestão da logística de captação de leite na Cooperativa Agropecuária Castrolanda (PR). Tal preocupação tem referências na reestruturação experimentada pelo setor e no processo de granelização da coleta, que viabilizou a implementação de nova logística. O modelo utilizou a heurística das economias de Clark e Wright (CW), minimizando a distância total percorrida, como uma proxy dos custos de transporte, sujeita às restrição de produção nas propriedades, capacidade dos tanques, tipo de caminhão acessivel nas estradas principais, secundárias e nas vias de acesso. As principais conclusões que podem ser extraídas deste trabalho referem-se às vantagens oferecidas pelo modelo desenvolvido em relação às sistemáticas empíricas e aos modelos comerciais importados, que foram originalmente desenvolvidos para solucionar problemas de otimização aplicáveis aos meios urbanos.

Palavras-chave: agronegócio do leite, logística, pesquisa operacional.

\section{Introdução}

O agronegócio do leite tem sido marcado por transformações substanciais a partir dos anos de 1990. Em nível institucional, em 1992, o Estado deixou de tabelar os preços, nos diversos níveis, após mais de 45 anos de controle no mercado. No plano macroeconômico, a estabilização da economia (Plano Real) possibilitou um significativo crescimento da demanda por lácteos.

No tocante à produção primária, o incremento da atividade na região Centro-Oeste alcançou níveis extremamente significativos, colocando o estado de Goiás dentre os expoentes da produção nacional. Como resultado, a produção primária cresceu substancialmente, de 14,5 bilhões de litros em 1990 para 19,1 bilhões de litros em 1999, o que representou uma taxa de crescimento anual de $3,31 \%$, com um aumento de produtividade de $5,51 \%$ a.a. (Yamaguchi et al., 2001). Isso implicou colocar o Brasil como o $6^{\circ}$ maior produtor mundial (Brandão e Leite, 2001).

$\mathrm{O}$ crescimento da demanda também impulsionou as importações e o Brasil tornou-se o oitavo maior importador mundial de leite, o que representou uma média de comprometimento de divisas de US\$ 400 milhões/ano nos anos 90 (Martins, 2001).

No segmento industrial, as transformações implicaram em um intenso processo de aquisições, uma significativa reestruturação produtiva e a reorganização dos canais de comercialização. Muitos laticínios, com atuação em mercados regionais, foram adquiridos por grandes empresas nacionais e principalmente transnacionais. Novas plantas industriais foram estruturadas, com maior capacidade de processamento, e houve racionalização na distribuição, 
com a reorganização dos canais viabilizados por inovações no setor, no nível da produção, da embalagem e da logística (Martins et al., 1999).

No plano operacional, as transformações tiveram como foco a qualidade da matéria-prima, materializadas na granelização da coleta e do transporte e no resfriamento do leite na propriedade. Até a primeira metade dos anos noventa, o leite era ordenhado nas propriedades e levado diretamente até as usinas de beneficiamento em caminhões comuns, acondicionado em latões. A partir da segunda metade da década, foi introduzida, e rapidamente disseminada, a coleta a granel no Brasil, com transporte feito por caminhões com tanques isotérmicos. A implantação do sistema de coleta de leite a granel, no Brasil, transcorre de forma rápida a ponto de ser considerada como uma das mais aceleradas do mundo, indo ao encontro do Programa Nacional de Qualidade do Leite (PNQL), instituído pelo Ministério da Agricultura e do Abastecimento. Essa transição ocorreu de forma mais intensa no Estado do Rio Grande do Sul, que atualmente possui $100 \%$ do leite produzido na forma granelizada. O PNQL prevê a granelização total nas regiões Sul, Sudeste e Centro-Oeste até o ano de 2005 e, até o ano de 2011, nas regiões Norte e Nordeste. Nos principais estados produtores, a coleta granelizada já predomina dentre os sistemas de captação utilizados (Figura 1).

A coleta de leite a granel produz inúmeras transformações no agronegócio do leite. Esse sistema de coleta re-

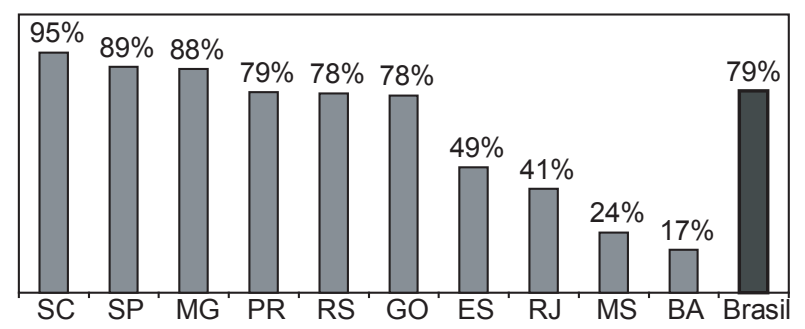

Figura 1. Percentual de granelização do leite captado pelas cooperativas, segundo os estados brasileiros (2002). Fonte: Nogueira Netto (2003). duz os custos de captação da matéria-prima, elimina postos de resfriamento, aumenta a produtividade na fazenda e aumenta sensivelmente a qualidade do leite que chega para processamento nas indústrias. O processo consiste na coleta do produto "in natura" resfriado nas propriedades e sua transferência diretamente do resfriador para os caminhões-tanques isotérmicos, por um mangote flexível e bomba especial auto-aspirante. Esse processo possibilita que o leite recolhido na propriedade conserve suas propriedades pelo resfriamento imediato (Sobrinho et al., 1995; Jank e Galan, 1998).

A introdução do conceito de logística de transporte no agronegócio do leite possibilita o fechamento de postos de resfriamento, a redução de rotas de coleta e o aumento da quantidade de carga transportada por veículo, resultando em significativas economias nos custos de transporte (Martins et al.,1999) e em ganhos em qualidade (Sobrinho et al., 1995). A Tabela 1 detalha alguns parâmetros que podem ilustrar estes ganhos.

Os novos procedimentos adotados referentes às operações logísticas, contudo, deram-se, em geral, de modo empírico. Com a pressão permanente de produtos importados, quase sempre subsidiados na origem, e o distanciamento da produção em relação aos principais centros de consumo, as empresas reconhecem a dificuldade de incorporação de novas ferramentas que reduzam o custo de captação e otimizem as linhas, a frota e a localização dos postos de resfriamento.

No Brasil, somente as maiores empresas do setor estão implantando processos de racionalização com uso de ferramenta específica. Pela inexistência de alternativas que considerem as características nacionais e de negócios rurais, estas empresas estão se valendo de softwares importados customizados (dentro de suas restrições originais de aplicabilidade ao setor) e desenvolvidos originalmente à captação de lixo urbano ou a distribuição de gás de cozinha.

O objetivo deste artigo é a apresentação dos resultados do desenvolvimento e implementação de um software para captação de leite na Cooperativa Agropecuária Cas-

Tabela 1. Parâmetros de comparação coleta granel e coleta em latões para o leite na Cooperativa Sudcoop (Medianeira - PR).

\begin{tabular}{lrr}
\hline \multicolumn{1}{c}{ Parâmetros } & $\begin{array}{c}\text { Coleta em latões } \\
\text { (dezembro de 1992) }\end{array}$ & $\begin{array}{c}\text { Coleta a granel } \\
\text { (maio de 1999) }\end{array}$ \\
\hline Recepção de leite & $8.690 .820,0$ & $10.361 .905,0$ \\
Número de produtores & $7.389,0$ & $3.693,0$ \\
Média litros/dia/produtor & 37,9 & 90,5 \\
Número de linhas & 135,0 & 62,0 \\
Número de veículos & 142,0 & 52,0 \\
Número de viagens/dia & 173,0 & 72,0 \\
Volume médio/veículo & $1.974,0$ & $6.428,0$ \\
Temperatura média leite $\left({ }^{\circ} \mathrm{C}\right)$ & 22,0 & 6,2 \\
\hline
\end{tabular}

Fonte: Fonseca (2001) 
trolanda no Estado do Paraná, local em que foi concebida uma ferramenta de gestão ágil e segura (software específico) que possibilitou o aprimoramento do processo de captação de leite junto aos produtores rurais, nos aspectos custos de captação e frota.

A próxima seção apresenta o formato geral do problema e o modelo utilizado, bem como a heurística utilizada e os dados. Na seção 3, são apresentados e discutidos os resultados obtidos no processo de racionalização, apresentando a formação de rotas e avaliando alguns indicadores relativos à eficiência da coleta roteirizada, algumas estratégias possíveis para aprimoramento dos resultados e os resultados em termos de custos da coleta, por região e rota. Finalmente, contextualizam-se os resultados em relação ao efeito da implementação da coleta racionalizada e ao novo processo de roteirização gerenciada com apoio de ferramenta específica na empresa.

\section{Material e métodos}

Nesta seção, são apresentadas mais informações sobre o processo a ser otimizado, com detalhamento da área geográfica atingida, modelagem, definição de agrupamentos e características dos dados utilizados.

\subsection{Cooperativa Agropecuária Castrolanda}

A Cooperativa Agropecuária Castrolanda foi fundada por imigrantes holandeses, no ano de 1951, em Castro (PR). Encontra-se inserida no segmento agropecuário, tendo o leite como um dos principais produtos comercializados. A cooperativa reúne 563 associados, 206 bovinocultores e um rebanho de 13.000 vacas, para uma produção média em torno de 1.200 litros/dia/fornecedor (informações disponíveis no sítio www.castrolanda.coop.br).

A Castrolanda participa do pool ABC - Arapoti, Batavo e Castrolanda -, desde sua criação em 2001, que comercializa conjuntamente mais de 400 mil litros de leite resfriados por dia. A função do pool é captar leite de forma eficiente e negociar a venda dos consorciados nas melhores condições possíveis, sem a industrialização ou qualquer beneficiamento.

As características da região de atuação da Castrolanda podem ser resumidas no elevado volume de leite e distâncias relativamente pequenas entre as propriedades, excelente padrão de sanidade do produto, boa infra-estrutura de estradas rurais, elevado nível de tecnificação do produtor e baixa sazonalidade da produção.

\subsection{Processo de formatação do problema e da modelagem}

O processo de coleta de leite atualmente desenvolvido pela Cooperativa Castrolanda é empírico. A roteirização é preparada semanalmente de forma a se compatibilizar com as ordenhas dos produtores e a capacidade dos tanques de resfriamento. As coletas ocorrem diariamente, gerenciando-se a frota disponível.

Existem dois tipos de coletas: a coleta diária e em 48 horas. O critério para definição do período de coleta é a relação entre a produção diária e a capacidade do tanque de resfriamento. Caso o volume, que possa ser armazenado nos tanques, seja pelo menos o dobro da produção diária, a coleta ocorrerá a cada dois dias. Senão, a coleta será diária.

Foram formadas linhas, considerando-se o tempo para coleta e as quantidades totais coletadas nas propriedades das linhas. Algumas destas são fixas e outras móveis, isto é, podem ser reformatadas de acordo com as necessidades de captação e disponibilidade de veículos (capacidade de transporte).

O leite é vendido na modalidade FOB, num volume médio diário próximo dos 500.000 litros. A cooperativa informa as quantidades a serem entregues a seus clientes, com as respectivas localizações, e as empresas tomam as decisões quanto às propriedades a serem coletadas. Nesse processo, a coleta é organizada pelos prestadores do serviço, como uma atividade de apoio aos compradores. Este percurso não tem remuneração específica, pois o comprador paga a quilometragem relativa à transferência e a esta adiciona $100 \mathrm{~km}$.

Os destinos são bastante regulares, pois existem contratos que garantem determinadas quantidades periódicas que são entregues na própria Cooperativa Batávia, localizada em Carambeí, integrante do pool, em localidades como Londrina, Lobato e Toledo (PR): Araçatuba, Guaratinguetá, Itararé, Araras, Ribeirão Preto e Buri (SP), Araquari (SC), Poços de Caldas (MG) e Itumbiara (GO). Existem, porém, vendas eventuais a clientes não regulares.

Os veículos utilizados atualmente são toco (capacidade de 8.500 litros), truck (capacidade de 12.300-13.500 litros) e carreta (capacidade de 19.000-26.500 litros) e as rotas são basicamente fixas, com pequenas alterações para o período de pico da safra.

Um banco de dados sobre as propriedades foi criado, sendo estabelecidas as variáveis relevantes no caso, a saber: posicionamento geográfico; tanque de resfriamento (capacidade e marca); avaliação das condições de acesso de veículos; horário das ordenhas. Foram visitadas 461 propriedades para o levantamento de tais informações.

Outro fator importante para o planejamento está no fato da escala de produção ser bastante diferente entre os produtores. A variação registrada esteve entre 70 e 27.000 litros/dia. Em termos de modelagem, essas heterogeneidades podem ter repercussões no processo de formação de rotas para veículos com grandes diferenciais de capacidade de transporte.

Observa-se, também, a ocorrência de diferenciação das quantidades produzidas entre os períodos de safra (meses de maio-outubro) e entressafra (novembro-abril). $\mathrm{O}$ aumento da produção no período de safra, implica a 
necessidade de que as linhas sejam refeitas, pois muitos produtores que tinham coleta a cada 48 horas passam a ter coleta diária.

Por último, como fator a ser considerado na roteirização da coleta, está o fato de que alguns produtores necessitam que a coleta seja efetuada diariamente, enquanto que outros podem ter a coleta a cada 48 horas, em função da capacidade do tanque de resfriamento e da produção diária na propriedade.

\subsection{Modelo de racionalização}

A racionalização da coleta de leite implica definir matematicamente o modelo a ser estudado. Neste caso, trata-se do Problema de Percurso de Veículos em Vértices (PPV), uma vez que o objetivo é minimizar o percurso da frota passando por todos os produtores (vértices).

Conforme Gomes (1996), o PPV pode ser descrito como o problema de determinação de um conjunto ótimo de rotas de coleta/entrega a partir de um ou múltiplos depósitos, sobre um número de clientes dispersamente distribuídos em uma região geográfica, sujeito a um conjunto de restrições laterais (demanda máxima conduzida nos veículos, tempo de serviço, distância máxima, horários de atendimento, etc.). A formulação genérica do Problema de Percurso de Veículos pode ser colocada como se segue.

$$
\begin{aligned}
& \text { Minimizar } \sum_{v=1}^{n v} \sum_{i=1}^{n} \sum_{j=1}^{n} c_{i j} x_{i j}^{v} \\
& \text { Sujeito a } \\
& \sum_{v} \sum_{j} x_{i j}^{v}=1(i=2, \ldots, n), \\
& \sum_{i} x_{i p}^{v}-\sum_{j} x_{p j}^{v}=0(p=1, \ldots, n)(v=1, \ldots, n v), \\
& \sum_{j} q_{i}\left(\sum_{j} x_{i j}^{v}\right) \leq Q^{v}(v=1, \ldots, n v), \\
& \sum_{i} t_{i}^{v} \sum_{j} x_{i j}^{v}+\sum_{i} \sum_{j} t_{i j}^{v} x_{i j}^{v} \leq T^{v}(v=1, \ldots, n v), \\
& \sum_{j} x_{j 1}^{v} \leq 1(v=1, \ldots, n v), \\
& \sum_{j} x_{1 j}^{v} \leq 1(v=1, \ldots, n v), \\
& X=\left(x_{i j}^{v}\right) \in S, \mathrm{e} \\
& x_{i j}^{v} \in\{0,1\}(i, j=1, \ldots, n)(v=1, \ldots, n v) .
\end{aligned}
$$

em que:

$$
\begin{aligned}
& n=\text { número de vértices com demanda incluindo o depó- } \\
& \text { sito; } \\
& n v=\text { número de veículos; } \\
& c_{i j}=\text { custo do percurso do vértice } i \text { para o vértice } j ; \\
& Q^{v}=\text { capacidade do veículo } v ;
\end{aligned}
$$

$q_{i}=$ demanda no vértice $i$, em que $q_{l}=0$ e $q_{i} \leq Q^{v}, \forall i, v$;

$\mathrm{T}^{v}=$ tempo máximo permitido para o veículo $v$;

$t_{i}^{v}=$ tempo necessário para o veículo $v$ entregar ou receber no vértice $i$ (tempo de serviço em $i$ por $v$ );

$t_{i j}^{v}=$ tempo de percurso do veículo $v$ entre os vértices i $\mathrm{e} \mathrm{j}, t_{i j}^{v}=\infty$;

$x_{i j}^{v}=1$, se a ligação ij é usada pelo veículo v; 0 , caso contrário; e

$S=$ conjunto formado pelas restrições de quebras de subrotas ilegais que não incluem o vértice origem.

A função objetivo (Equação 1) deseja minimizar o custo total do percurso de um conjunto de veículos iguais ou distintos. As restrições (Equações 2 e 3 ) definem que cada vértice demanda é servido por exatamente um veículo. As Equações 4 consideram a continuidade do percurso (rota), ou seja, se um veículo entra em um vértice com demanda ele deve sair. As Equações 5 são as restrições de capacidade dos veículos e, de modo similar, as Equações 6 são relativas ao tempo total da rota. As Equações 7 e 8 garantem que a disponibilidade de veículos não será excedida. As restrições (Equação 9) representam a proibição de sub-rotas ilegais. Já as restrições (Equação 10) definem as variáveis de decisão do modelo.

No caso específico em estudo, existem algumas peculiaridades que precisam ser definidas e que, se não mudam radicalmente o modelo a ser desenvolvido, pelo menos, alteram a maneira como vão ser trabalhados. Uma delas diz respeito à aplicação da restrição de tempo, que não foi implementada, uma vez que a prática demonstrou que as rotas são curtas o suficiente para que os veículos as percorram dentro dos limites previstos. Outra diz respeito às alternativas de veículos na frota: Toco, Truck e Carreta, com capacidade de 8.500 litros, 12.700 litros e 22.000 litros, respectivamente. Cada propriedade a ser atendida tem restrições específicas quanto ao tipo de veículo que pode fazer a coleta. Algumas aceitam qualquer tipo, outras aceitam Truck e Toco e, por fim, existem as que aceitam apenas Toco. Isso se deve às condições das vias de acesso (estradas rurais e vias internas da propriedade) e ao tamanho do pátio para manobras.

$\mathrm{O}$ esquema de coleta também foi observado. Alguns produtores necessitam de coleta diária, enquanto outros podem ter a coleta feita em dias alternados, uma vez que os seus tanques de armazenamento têm capacidade suficiente para estocar a produção de dois dias.

Tendo em vista tais restrições, foi necessário buscar uma heurística que pudesse ser modificada a fim de atender a essas peculiaridades sem que houvesse um prejuízo considerável para o resultado final.

A heurística utilizada foi a das economias de Clarke e Wright (CW). Segundo Novaes (2001), essa heurística 
é bastante conhecida, sendo ainda muito utilizada como parte de outros procedimentos. Foi originalmente desenvolvida para resolver o problema clássico de roteamento de veículos. Baseia-se na noção de economias, que pode ser definido como o custo da combinação, ou união, de duas sub-rotas existentes. Trata-se de uma heurística iterativa de construção baseada numa função gulosa de inserção. O algoritmo é bastante apropriado para o problema em questão, uma vez que permite a limitação do tipo do caminhão e, por não requerer grande capacidade computacional, ser de fácil implementação.

Assume-se, inicialmente, que cada cliente é servido por um veículo, constituindo, assim, rotas de ida e volta entre o depósito e o cliente. Seja $c_{i j}$ a função da viagem entre um cliente $i$ e um cliente $j$, pode ser definida a partir de impedâncias, tais como distância percorrida, tempo de deslocamento, custo, ou uma combinação destas, por exemplo. Segundo a definição de Liu e Shen (1999), duas rotas, contendo os clientes $i$ e $j$ podem ser combinadas, desde que $i$ e $j$ estejam ou na primeira ou na última posição de suas respectivas rotas, e que a demanda total das rotas combinadas não ultrapasse a capacidade do veículo.

Em cada iteração, todas as combinações de rotas possíveis são analisadas por:

$$
\mathrm{Tij}=\mathrm{cid}+\mathrm{cdj}-\mathrm{cij}
$$

em que: $d$ representa a base operacional e $T_{i j}$ o ganho obtido pela união das duas rotas. As duas rotas, que produzirem a maior economia de combinação, são unidas. Por ser sempre escolhida a maior economia dentre as possíveis, a função de escolha é dita gulosa. Como a cada nova combinação de sub-rotas as economias são novamente calculadas e atualizadas para a próxima combinação de sub-rotas, o método é dito iterativo (Liu e Shen, 1999).

Para melhor se entender este método, pode-se dizer que na escolha de dois pontos $i$ e $j$ para constituir a seqüência de um roteiro, procura-se selecionar o par com maior valor do ganho $T_{i, j}$. Há combinações, no entanto, que violam as restrições de tempo, capacidade, etc., não sendo, por isso, factíveis. O método explora esse conceito, sendo descrito a seguir:

1. Calcular os ganhos $T_{i, j}$ para todos os pares $i, j(i \neq j, i \neq$ $d$ e $j \neq d$ );

2. Ordenar os pares $i, j$ na ordem decrescente dos valores do ganho $T_{i, j}$;

3. Começar pelo par $i, j$ com maior ganho $T_{i, j}$ e proceder na seqüência obtida em; e

4. Para um par de nós $i, j$, correspondente ao $K$-ésimo elemento da seqüência (2) verificar se $i$ e $j$ estão ou não incluídos em um roteiro já existente:

a) Se $i$ e $j$ não foram incluídos em nenhum dos roteiros já abertos, então criar um novo roteiro com os nós $i$ e $j$;

b) Se exatamente um dos pontos $i$ ou $j$ já pertence a um roteiro pré-estabelecido, verificar se esse ponto é o primeiro ou último do roteiro (adjacente ao nó $d$-depósito). Se isso ocorrer, acrescentar o arco $i$, $j$ a esse roteiro. Caso contrário, passar para a etapa seguinte, saltando o par $i, j$;

c) Se ambos os nós $i$ e $j$ já pertencem a dois roteiros préestabelecidos (roteiros diferentes), verificar se ambos são extremos dos respectivos roteiros (adjacentes ao nó $d$ ). Nesse caso, fundir os dois roteiros em um só. Caso contrário, passar para a etapa seguinte, pulando o par $i, j$;

d) Se ambos os nós $i$ e $j$ pertencem a um mesmo roteiro, ir para a etapa seguinte; $\mathrm{e}$

e) Continuar o processo até que a lista completa de "ganhos" seja exaurida. Se sobrar algum ponto não incluído em nenhum roteiro, deverão ser formados roteiros individualizados, ligando o depósito a cada ponto e retornando à base.

Este é o algoritmo para identificar se os pontos i e j estão incluídos numa rota.

Se $i$ e $j$ não estão em nenhum roteiro, então,

criar um roteiro com $i$ e $j$.

\section{Senão,}

se $i$ ou $j$ estiver em um roteiro, então:

se este nó é um extremo de um roteiro, então, agregar $i$ e $j$ ao roteiro;

senão, abandonar o par $i$ e $j$.

Senão,

se $i$ e $j$ estiverem em roteiros diferentes, então: se $i$ e $j$ são extremos de seus roteiros, então, unir os dois roteiros; senão,

Senão, abandonar o par $i$ e $j$.

abandonar o par $i$ e $j$.

\subsection{Dados}

A dispersão geográfica das propriedades e a ausência de um sistema de georreferenciamento das estradas rurais constituíam-se numa dificuldade adicional que tornavam singular o problema e afastavam-se das experiências de problemas conhecidos.

O conjunto de propriedades foi testado utilizando-se a metodologia de p-medianas, mas os resultados obtidos para os agrupamentos apresentavam alta dispersão no número de produtores. Dessa forma, a roteirização obtida ficou prejudicada, considerando-se as alternativas de até três tipos de caminhão para coleta em cada um dos agrupamentos, o que levava os caminhões a rodarem, em muitos casos, com alta capacidade ociosa de carga.

Assim, dentro destas adversidades, o processo de agrupamento foi feito com base em localização geográfica, tendo como referência algumas cidades da área pesqui- 
sada. Estes agrupamentos foram definidos como: Ponta Grossa, Carambeí-Castro, Piraí, Castrolanda e Carambeí, sendo, as duas últimas, por reunirem propriedades que permitem acesso de carretas para coleta. Os agrupamentos Piraí e Ponta Grossa são caracterizados como compostos de pequenos produtores; Carambeí e Castrolanda reúnem produtores com grandes volumes médios diários e com pequena dispersão geográfica; o agrupamento Carambéi-Castro é o que reúne maior número de produtores, porém com grande diversidade tecnológica e de produção diária, e caracteriza-se por diversidades quanto a avaliação de acesso de veículos às propriedades.

Para cada agrupamento, foi gerada uma matriz de distâncias entre os produtores, a partir da distância euclidiana. Embora a literatura indicasse 1,3 para distâncias rodoviárias e meios urbanos, o parâmetro, foi constatado, pelo confronto dos resultados com a quilometragem tirada empiricamente, pois a especificidade local de algumas regiões, tais como circunstâncias de relevo e da característica de estrada rural, não corroboraram tais parâmetros. Assim, para regiões com características urbanas, em que as propriedades são localizadas muito próximas ou mesmo nos centros urbanos, manteve-se a indicação da literatura, 1,3, o que prevaleceu nos casos de Castrolanda, Carambeí e Castro-Carambeí. Nos outros casos, os parâmetros utilizados referem-se aos valores empiricamente observados em comparação com a distância euclidiana inicialmente estimada, tendo sido 2,0, para Piraí do Sul e 3,0, para Ponta Grossa.

O processo de coleta implicava a saída do veículo da base operacional, a visita às propriedades e finalizava com o retorno ao ponto da partida. A base operacional foi localizada na cidade de Carambeí, sede da maior prestadora de serviços, uma vez que Castrolanda, atualmente, não presta serviços de logística, pois a modalidade de venda utilizada é FOB.

Os valores relativos à produção diária por propriedade utilizados para esta simulação referem-se à média entre os valores mínimos e máximos registrados para o ano de 2003 e foram cedidos pela cooperativa.

As demais informações relevantes, tais como, localização das propriedades, capacidade do tanque de resfriamento e avaliação das vias de acesso, foram levantadas pela equipe envolvida no projeto.

\section{Resultados}

Nesta seção, são apresentados os resultados obtidos no processo de racionalização, com a formação de rotas e demais indicadores produzidos, relativos à eficiência da coleta roteirizada, bem como resultados de modelos pensados como estratégias possíveis para aprimoramento dos resultados, e os resultados em termos de custos da coleta, por região e rota.

\subsection{Resultados da racionalização}

Considerando-se a especificidade do produto, que tem de ser coletado no prazo limite de 48 horas após a ordenha, o modelo desenvolvido gera informações para dois dias de coleta, o que implica "visitar" todas as propriedades no período. Chama-se a atenção para a alta estabilidade dos resultados, o que tem implicações logísticas importantes, em termos de previsão da coleta e investimentos na frota.

A coleta organizada em 31 rotas diárias implicaria rodar 6,7 mil km diariamente (Figura 2), captando um volume médio de 392,3 mil litros de leite (Figura 3).

As rotas são razoavelmente curtas (baixa quilometragem), sinalizando para a economicidade da coleta comparativamente a outras regiões brasileiras, particularmen-

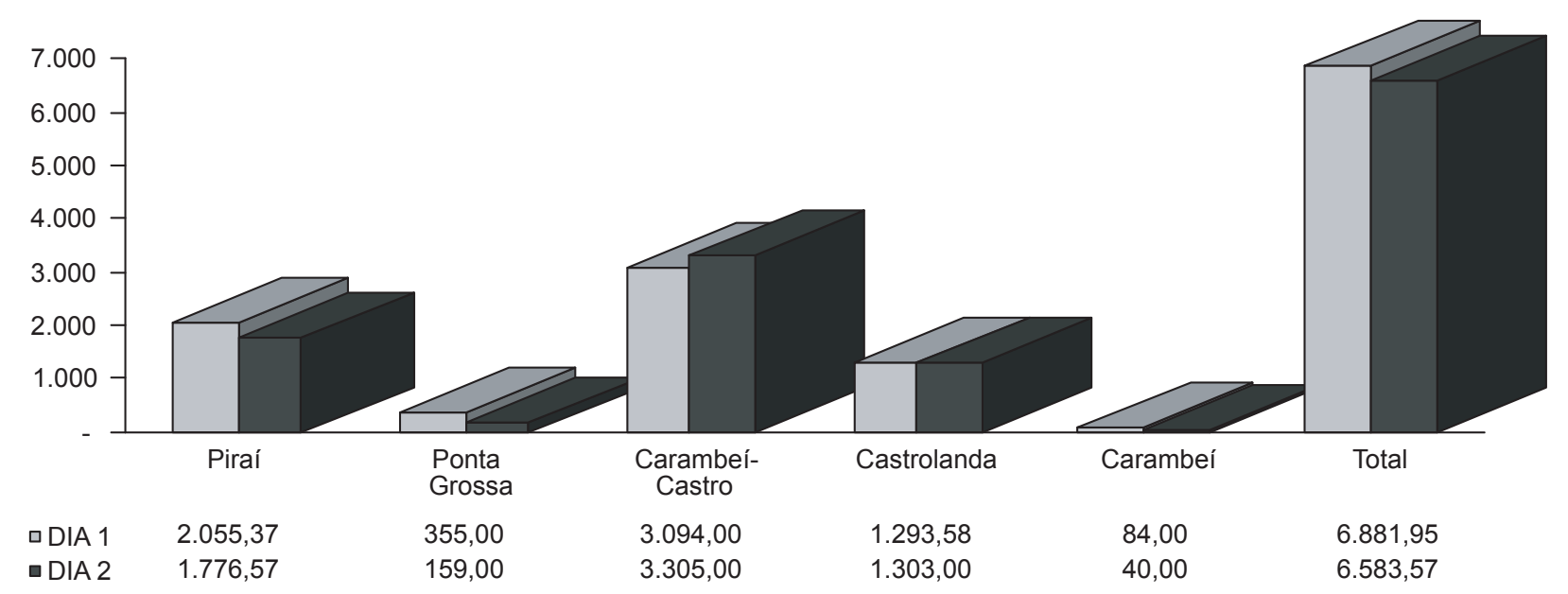

Figura 2. Quilometragem total percorrida para a captação de leite, Cooperativa Castrolanda, segundo os agrupamentos. Fonte: Resultados da pesquisa. 
te as regiões de expansão recente de Goiás, Mato Grosso e Pará. Como o volume médio de leite coletado nas propriedades também é alto, dado o nível de especialização do produtor, a densidade média é extremamente elevada para a realidade brasileira, com destaques para os resultados do agrupamento "Carambeî" (Figura 4).

\subsection{Simulações}

A título de elaboração de cenários para avaliação de estratégias, algumas simulações foram realizadas, com o objetivo de discutir formas de racionalizar o processo de coleta, com alterações nos veículos e nas necessidades de coleta.

Em termos conceituais, os modelos de referência dos resultados referem-se a simulações. O chamado modelo original refere-se aos resultados obtidos pelo processo de modelagem, na forma real. O modelo truck refere-se a uma simulação, considerando-se que a coleta poderia ocorrer apenas com a utilização de trucks e carretas (portanto, sem uso do veículo toco), procurando dimensionar as vantagens econômicas de se aumentar a capacidade média dos veículos utilizados. O modelo toco refere-se a uma outra simulação, considerando que a coleta poderia ocorrer apenas com a utilização de tocos e carretas (portanto, sem modelo truck), procurando dimensionar as vantagens econômicas de se otimizar algumas linhas que resultavam em coleta com grande capacidade ociosa dos veículos. O modelo $\mathbf{4 8}$ horas considerava que todos os produtores tinham tanques de resfriamento com capacidade igual ou superior a dois dias de produção, implicando a viabilidade da coleta a cada dois dias (48 horas), o que poderia apresentar significativa vantagem no custo da coleta.

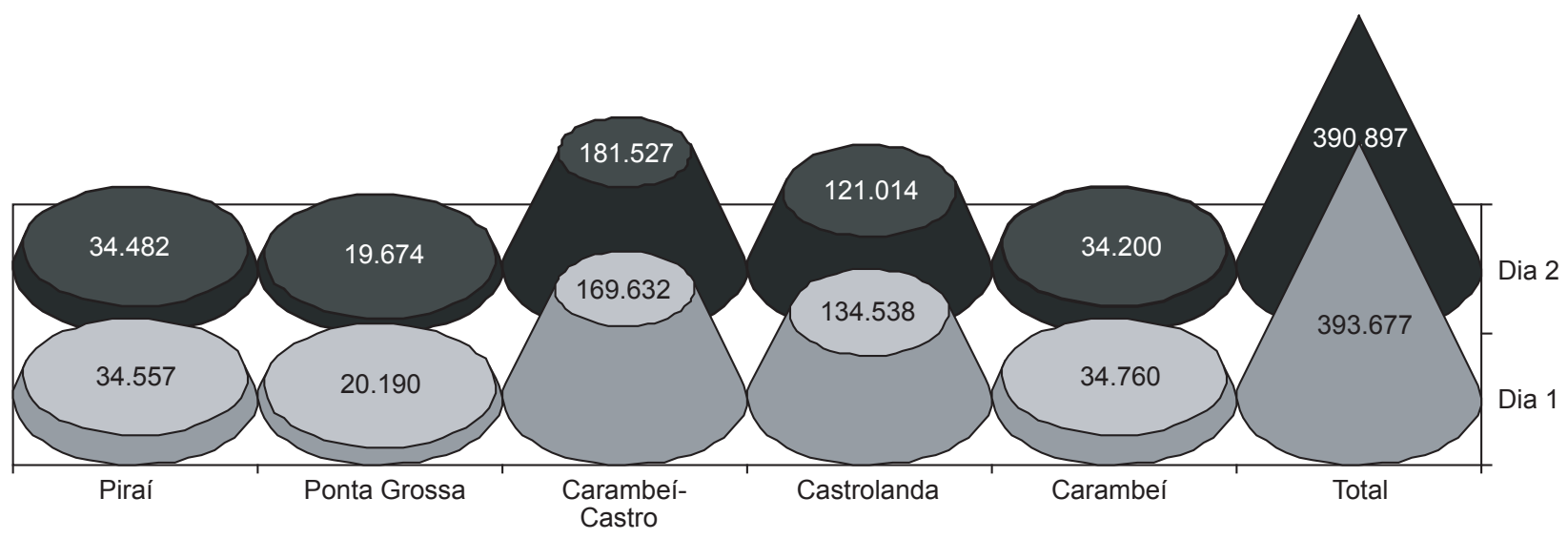

Figura 3. Litros de leite coletados, por agrupamento, dias 1 e 2, Cooperativa Castrolanda Fonte: Resultados da pesquisa.

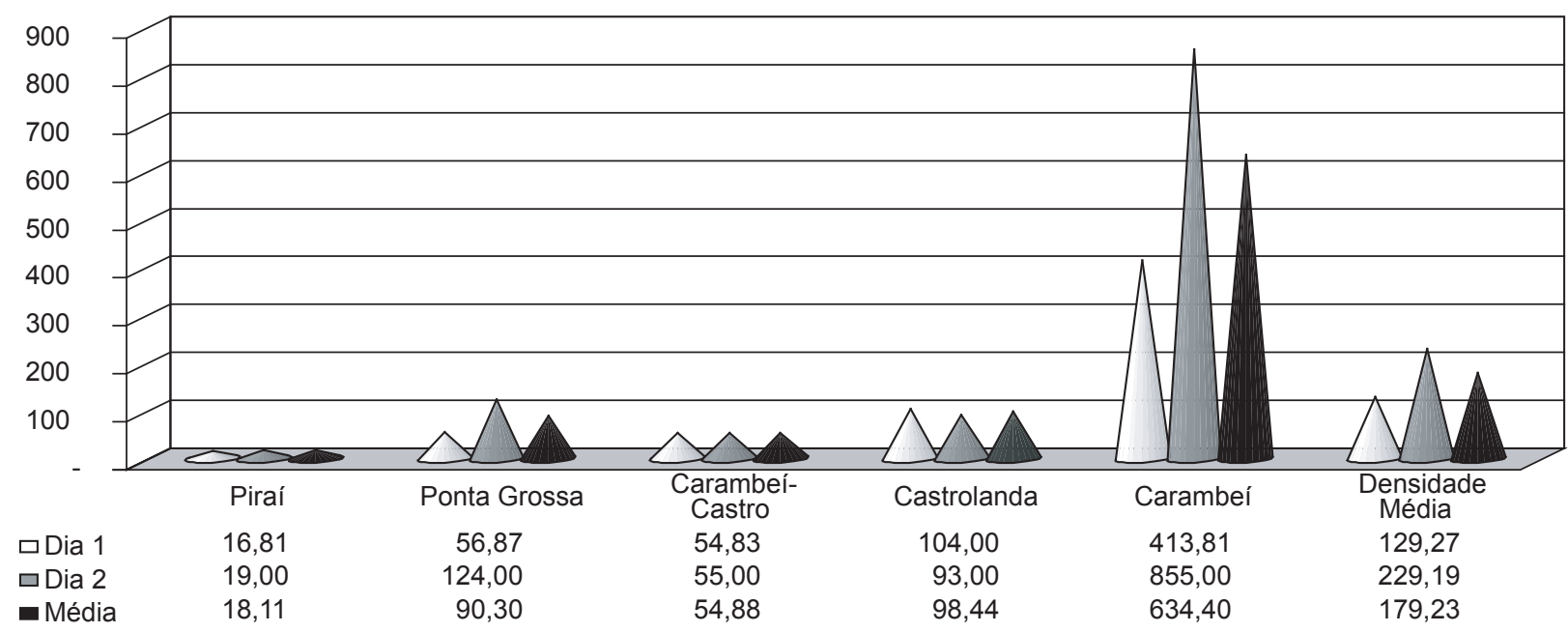

Figura 4. Densidade da coleta $(1 / \mathrm{km})$, por agrupamento, dias 1 e 2, Cooperativa Castrolanda Fonte: Resultados da pesquisa. 
Os resultados são apresentados (Figura 5) com base nos diferenciais de quilometragem média diária rodada, para os diferentes agrupamentos. Foram registradas as vantagens da coleta 48 horas para todos os parâmetros, sendo que este resultado reflete o peso das economias proporcionadas nas rotas específicas de carretas (Castrolanda e Carambeí), ainda que o resultado negativo seja consistente para todos os agrupamentos é em grande parte superior aos outros modelos simulados. Porém, a viabilização deste sistema implica alto custo de capital para a aquisição e preparação das instalações, para aumentar a capacidade de armazenamento nas propriedades. Por outro lado, a coleta com veículos toco adicionou quilometragem rodada ao sistema.

\subsection{Estimativas de custos de transporte de leite}

O sistema de custeio adotado nesta fase de implantação de um novo processo logístico foi o custo-padrão. Este sistema objetiva determinar ou estabelecer medidas de comparação que permitam efetuar o controle dos custos. Segundo Horngren (1978, p. 198) 'Os custos-padrão são custos pré-determinados que deveriam ser atingidos dentro de operações eficientes. Servem para aferição de desempenho, para fazer orçamentos úteis, para nortear preços, para obter um custo significativo de produto e para economia de escrituração".

Os objetivos do custo-padrão são:

- Avaliação do desempenho e eficácia operacional da empresa, mediante comparação do custo estimado e custo real;

- Apuração das responsabilidades, mediante identificação das causas das variações; e

- Oportunidade de redução de custos, mediante ações corretivas sobre as variações ocorridas.

O custo-padrão deve ser cuidadosamente calculado, tendo em vista a repercussão que este pode representar dentro da empresa. É de fundamental importância sua correta estimativa, bem como sua constante revisão e adequação a fim de incorporar mudanças tecnológicas ou mesmo operacionais, para estabelecimento de padrões futuros.

Para o caso do custeamento na prestação de serviços de transporte, a utilização do custo-padrão pode ser de grande importância como ferramenta de controle e acompanhamento dos custos. Para tanto, é necessário que se estabeleça um custo-padrão que reflita a realidade de uma empresa ou de um negócio e que, de fato, se realize acompanhamento dos resultados mediante comparação entre os custos orçado (padrão) e realizado (custo real), procedendo às devidas correções que se fizerem necessárias.

Cabe, inicialmente, considerar que o custo-padrão orçado para a coleta de leite considerou, como veículos utilizados para fins de apuração de custos, o VW 23.210 truck $(12.700 \mathrm{~kg})$ e o VW 15.180 toco $(8.500 \mathrm{~kg})$ e, para carretas, o veículo Mercedes-Benz, com desempenhos e necessidades de manutenção apurados no mercado e nos manuais dos respectivos veículos.

A quilometragem média diária rodada pelos veículos e a carga média tracionada foram estimadas, tendo por base que em cerca de $50 \%$ do mês os veículos fazem duas rotas/dia, sendo utilizados os seguintes valores:

- toco: $300 \mathrm{~km} \mathrm{e} \mathrm{7,8} \mathrm{t;}$

- truck: $250 \mathrm{~km} \mathrm{e} 10,6 \mathrm{t}$; e

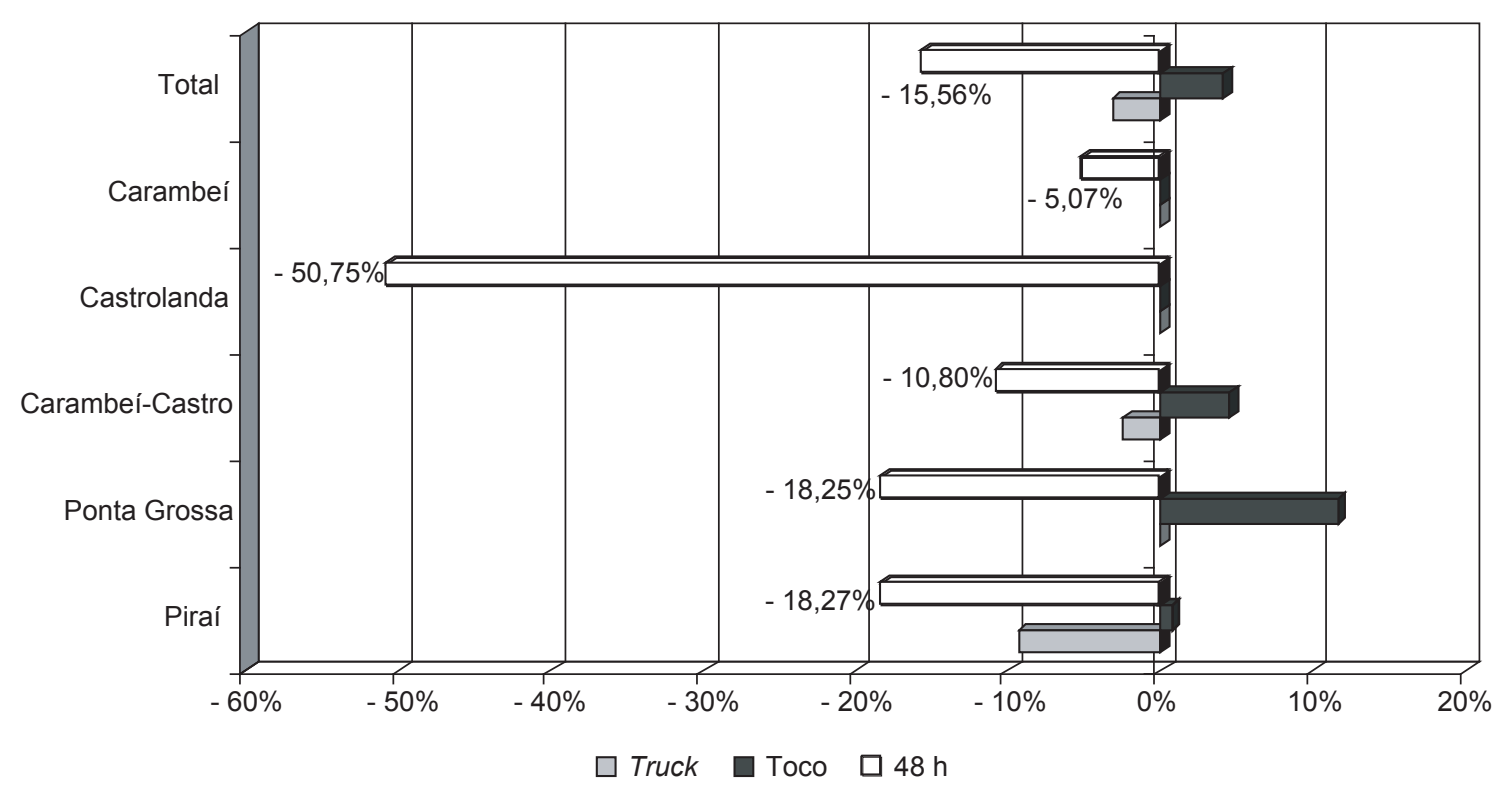

Figura 5. Comparações da quilometragem rodada (em \%) com os resultados originais Fonte: Resultados da pesquisa. 
- carreta: $250 \mathrm{~km}$ e $22 \mathrm{t}$.

A Tabela 2 mostra o custo de captação de leite (em $\mathrm{R} \$ / \mathrm{t}$, em $\mathrm{R} \$ / \mathrm{l}$ e em $\mathrm{R} \$ / \mathrm{km})$, segundo diferentes tipos de veículo. Conforme se observa, o volume transportado e a quilometragem rodada exercem influência significativa na redução dos custos de transporte, no tocante à contribuição ao rateio dos custos fixos da atividade.

No quadro comparativo dos veículos, destaca-se a economicidade da coleta com carretas. O princípio da escala da coleta por veículo mostrou-se bastante significativa, uma vez que a destinação do veículo truck representa um ganho de $29 \%$ em relação ao toco. A possibilidade de melhora ainda é mais favorável no caso do uso de carretas, implicando uma redução de custos de $25 \%$ em relação ao truck e quase $50 \%$ em relação ao toco. Porém, a realidade, muitas vezes, inviabiliza a aplicação desta lógica econômica em função de fatores adicionais, tais como a qualidade das vias de tráfego nos meios rurais, de acesso e pátios das propriedades.

Há que se considerar que estas vantagens da carreta apenas se concretizam, caso haja uma quantidade a ser coletada compatível com a capacidade do veículo, pois, de outra forma, os custos de rodar $(\mathrm{R} \$ / \mathrm{km})$ são desfavoráveis.

Com base nestes custos apurados, estimou-se a coleta diária dos cerca de 392 mil litros de leite em base por $\mathrm{R} \$ / \mathrm{km}$ e por $\mathrm{R} \$ /$ litro. O custo médio (entre os dias 1 e 2) estimado para a coleta com a remuneração da quilometragem foi de $\mathrm{R} \$ 6.203,04$ (Figura 6), o que significaria um custo unitário, de $\mathrm{R} \$ 0,92 / \mathrm{km}$.

Caso o pagamento ocorresse na base $\mathrm{R} \$ /$ litro, o custo diário da coleta seria de $\mathrm{R} \$ 8.004,75$ (Figura 7), equivalendo a um custo unitário de R \$ 0,20/litro. Este custo seria $23 \%$ inferior ao frete atualmente praticado no mercado regional ( $\mathrm{R}$ \$ 0,026/litro). No entanto, na prática, estes custos serão ainda menores porque a coleta já está quase atingindo 500 mil litros por dia, cerca de 65 mil além do volume total que foi utilizado para esta simulação operacional do modelo.

Para este adicional, entende-se que o acréscimo de quilometragem será ínfimo. Isto implica que a coleta ocorrerá com maior densidade $(\mathrm{L} / \mathrm{km})$, e os veículos reduzirão o nível de capacidade ociosa, fazendo convergir os custos nas bases $\mathrm{R} \$ / \mathrm{km}$ e $\mathrm{R} \$ /$ litro. Por exemplo, no caso do custo da coleta na base de remuneração $\mathrm{R} \$ /$ litro atingir o valor de $\mathrm{R} \$ 6.203,04$, o custo unitário do leite coletado seria de R \$ 0,016/litro, 38,46\% inferior ao valor praticado no mercado no momento.

\section{Considerações finais}

O objetivo desta pesquisa foi o desenvolvimento de uma ferramenta de gestão da logística de captação de leite na Cooperativa Agropecuária Castrolanda no Estado do Paraná. A ênfase no processo de racionalização foi dada nos aspectos custos de captação e na racionalização da frota.

Os resultados gerados proporcionam a possibilidade de um gerenciamento eficiente da logística, à medida que são racionalizados os custos da coleta e a frota utilizada. A racionalização diária das rotas permite a transparência quanto aos resultados econômicos da frota, viabilizando alternativas de gerenciamento quanto à destinação dos veículos, busca de negócios complementares no período de entressafra e utilização de parcerias com autônomos, para a redução do volume de capital imobilizado nos ativos (caminhões) de alta especificidade.

Fundamentalmente, a racionalização da coleta proporciona o melhor gerenciamento das variáveis mais relevantes do custo de captação, que são o volume de leite coletado, a quilometragem percorrida na coleta, que formam o indicador da densidade (litros de leite por $\mathrm{km}$ ), e o número de veículos apropriados às condições da coleta.

As principais vantagens oferecidas pela ferramenta

Tabela 2. Custos, distância percorrida e volume transportado na captação mensal de leite, dea acordo com os veículos

\begin{tabular}{|c|c|c|c|c|c|c|}
\hline Custos/Veículo & R\$/mês & km/mês & $\mathbf{R} \$ / \mathbf{k m}$ & t/mês & $\mathbf{R} \$ / \mathbf{t}$ & $\mathrm{R} \$ / \mathbf{l}$ \\
\hline Toco & & 13.250 & & 356 & 28,08985 & 0,0281 \\
\hline Fixos & $5.945,00$ & & 0,44037 & & & \\
\hline Variáveis & $4.053,03$ & & 0,30022 & & & \\
\hline Total & $9.998,03$ & & 0,74059 & & & \\
\hline Truck & & 11.250 & & 478 & 19,92912 & 0,0199 \\
\hline Fixos & $4.799,93$ & & 0,42666 & & & \\
\hline Variáveis & $4.726,19$ & & 0,42011 & & & \\
\hline Total & $9.526,12$ & & 0,84677 & & & \\
\hline Carreta & & 11.250 & & 990 & 15,41870 & 0,015 \\
\hline Fixos & $6.242,83$ & & 0,55492 & & & \\
\hline Variáveis & $9.021,68$ & & 0,80193 & & & \\
\hline Total & $15.264,51$ & & 1,35685 & & & \\
\hline
\end{tabular}

Fonte: Dados da pesquisa. 


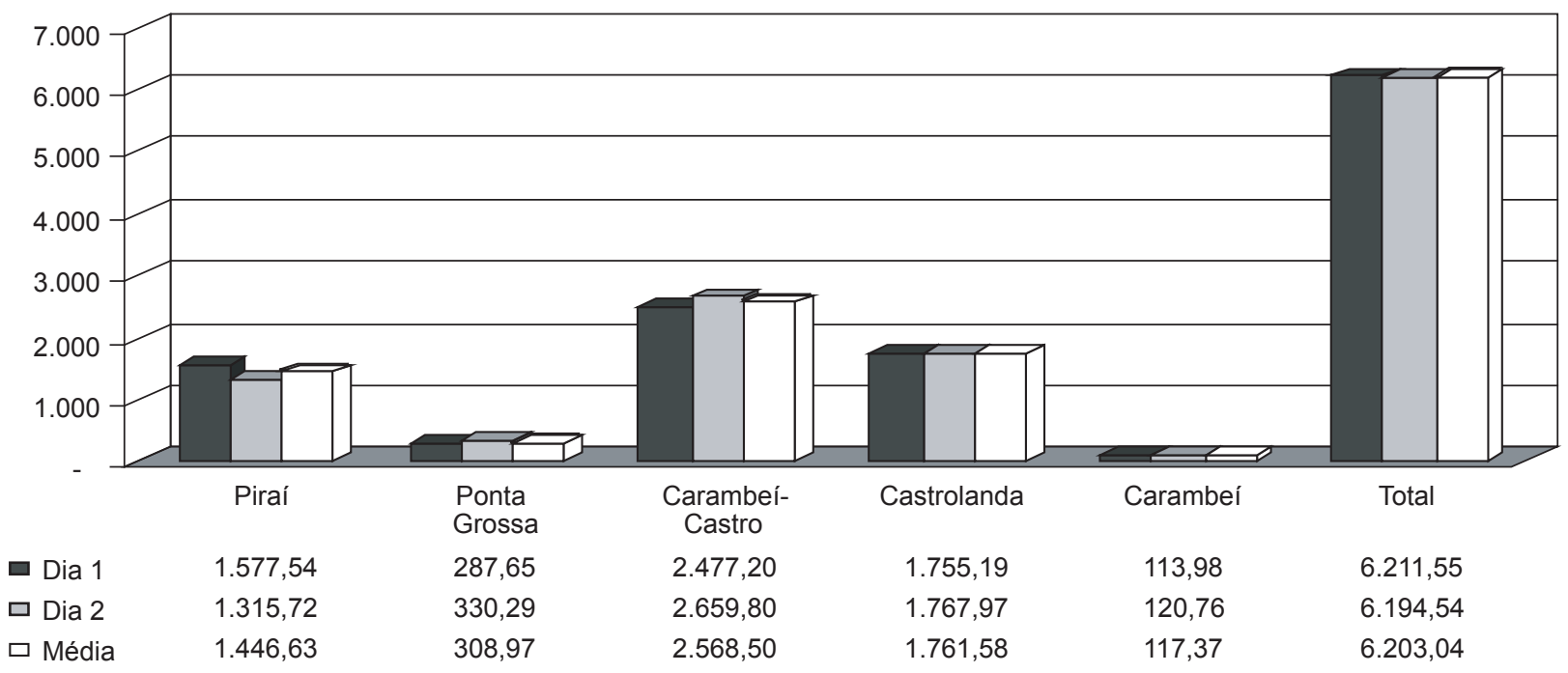

Figura 6. Custo total da coleta, segundo os agrupamentos, em $\mathbf{R} \$ / \mathbf{k m}$ Fonte: Resultados da pesquisa.

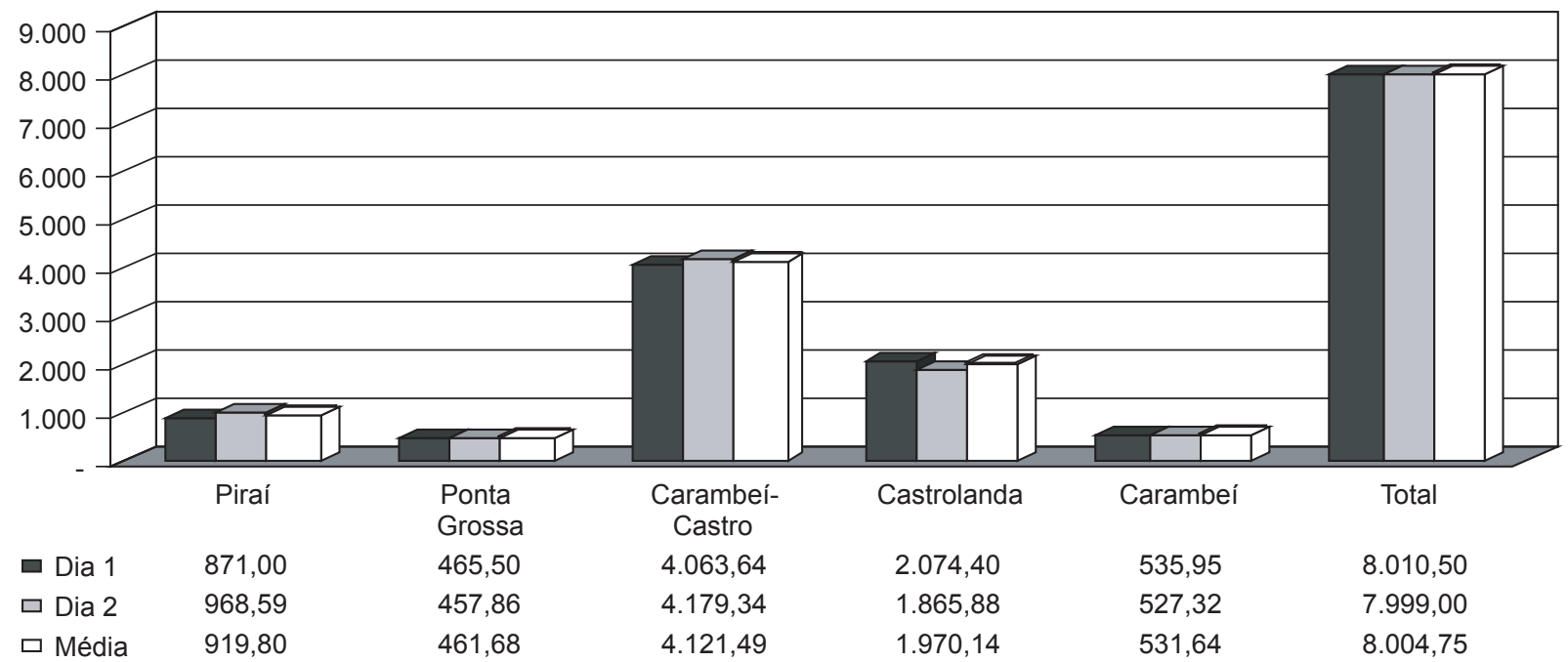

Figura 7. Custo total da coleta, segundo os agrupamentos, em $\mathrm{R} \$ /$ litro Fonte: Resultados da pesquisa.

desenvolvida em relação às sistemáticas empíricas e aos modelos comerciais importados podem ser enumeradas como:

- Foi desenvolvida especificamente para solucionar o problema da gestão logística de captação de leite, em nível de propriedades;

- Permite racionalização com frota diversificada;

- Permite avaliação específica das condições das propriedades; e

- Permite gerar relatórios específicos de acordo com o interesse da Castrolanda.

Considerando-se que o processo anteriormente em uso baseava-se no critério FOB, isto é, o comprador do leite arcava com os custos da coleta, a cooperativa não tinha informações precisas e sistematizadas sobre os parâmetros mais relevantes da coleta: o custo $(\mathrm{R} \$ / \mathrm{l})$ e a densidade do transporte $(1 / \mathrm{km})$. Sendo assim, as tentativas de aferir a eficiência dos resultados eram inócuas.

Porém, a título de ilustração, foram apresentados alguns resultados construídos a partir de informações da empresa e dos prestadores do serviço. Deve-se ressaltar que um processo otimizado pode obter resultados reais ainda melhores à medida que aumentar a eficiência do transporte, isto é, aumentando o volume de leite captado sem o igual aumento da quilometragem. Neste caso, a estratégia da empresa de agregar novos produtores localizados nas áreas já atendidas e de estimular o aumento da 
produção dos produtores já integrados pode proporcionar melhoria ainda mais significativa.

Cabe ressaltar também que o domínio gerencial, agora possível, pode tornar-se uma variável estratégica para a empresa, por exemplo, alterar a forma de comercialização do leite para a base CIF, isto é, cobrando o preço entregue na porta do comprador, o que implica internalizar a logística.

Uma vez que tal processo seja implementado, os benefícios do projeto podem ser visualizados nos níveis:

- Aumento na renda do produtor, obtido pelos menores custos de transporte e com rateio adequado dos custos do transporte;

- Modernização do processo logístico, com aumento na eficiência na cadeia; e

- Sustentabilidade no desenvolvimento regional.

Uma vez que os seguidores do mercado passem também a adotar tal processo, os benefícios em nível de cadeia podem ser antevistos como:

- Sustentabilidade do negócio do leite nos pequenos e médios laticínios, com aumento na rentabilidade da empresa;
- Aumento da competitividade da cadeia nacional; e

- Aumento da produção nacional de leite.

O desenvolvimento de uma ferramenta de gestão nestes moldes pode implicar em profundas transformações na coleta de leite no Brasil. Atualmente, apesar da pressão de produtos importados, normalmente subsidiados na origem, o processo de coleta é feito, via de regra, de forma empírica. Isto não representa um atraso tecnológico do setor, haja vista que mesmo na logística desenvolvida para empresas industriais, ferramenta deste nível tecnológico não é algo tão presente no mercado, principalmente, uma ferramenta customizada. A disseminação do uso de ferramentas com este perfil pode ser um marco na logística do agronegócio brasileiro e do leite, particularmente, considerando-se o imenso potencial de redução de custos.

\section{Nota}

Com base na pesquisa desenvolvida pela Universidade Estadual do Oeste do Paraná (Unioeste) e pela Empresa Brasileira de Pesquisa Agropecuária (Embrapa)/Gado de Leite, financiada pelo Fundo Setorial Verde-Amarelo, Conv. Finep 01.02.0166.00.

\section{Referências Bibliográficas}

BRANDÃO, A. S. P.; LEITE, J. L. B. Características principais do comércio internacional de leite. In: GOMES, A. T.; LEITE, J. L. B.; CARNEIRO, A. V. (Ed.) O agronegócio do leite no Brasil. Juiz de Fora: Embrapa Gado de Leite, 2001. p.167-180.

CLARK, G.; WRIGHT, J. W. Scheduling of vehicles from a central depot to a number of delivery points. Operations Research, v. 12, p. 568-581, 1964.

CORDEAU, J. F.; GENDREAU, M.; LAPORTE, G.; PORVIN, J. Y.; SEMET, F. A guide to vehicle routing heuristics, Journal of the Operational Research Society, v. 58, p. $512-522,2002$.

FONSECA, L. R. L. Granelização do leite. Leite e Derivados, v. 10, n. 56, p. 66-68, 2001.

GOMES, M. J. N.; Contribuições para otimização em grafos e problemas de percursos de veículos: sistema SisGRAFO, 1996. 294p. Dissertação (Doutorado) - Universidade Federal do Rio de Janeiro (UFRJ), Rio de Janeiro, 1996.

HORNGREN, C. T. Contabilidade de custos : um enfoque administrativo. São Paulo: Atlas, 1978.

JANK, M. S.; GALAN, V. B. Competitividade do sistema agroindustrial do leite no Brasil In: CONGRESSO
NACIONAL DE LATICÍNIOS, 15, 1998, Juiz de Fora. Anais... Juiz de Fora: EPAMIG, 1998, p. 72-82.

LIU, Fuh-Hwa; SHEN, Sheng-Yuan, A metohd for vehicle routing problem with multiple vehicle types and time windows. Proc. Natl. Sci. Counc., v. 23, n. 4, p. 526536, 1999.

MARTINS, P. C. Efeitos de políticas públicas sobre a cadeia produtiva de leite em pó. In: VIEIRA, R. C. M. T.; TEIXEIRA FILHO, A. R.; OLIVEIRA, A. J.; LOPES, M. R. (Ed). Cadeias produtivas no Brasil: Análise da competitividade. Brasília: Embrapa/Secretaria de Administração Estratégica, 2001. p. 239-272.

MARTINS, R. S., SANTOS, C. V., TEIXEIRA, S. R. Alterações da rede logística e expansão do mercado de leite longa vida no Brasil. Organizações rurais e agroindustriais, Lavras, v. 1, n. 2, p. 55-69, 1999.

NOGUEIRA NETTO, V. Inserção do Brasil no mercado internacional de lácteos. SEMINÁRIO REMOVENDO OBSTÁCULOS PARA O CRESCIMENTO DA EXPORTAÇÃO DE LÁCTEOS DO BRASIL, 1. Belo Horizonte, 2003. (Palestra apresentada no evento).

NOVAES, A. G. Logística e gerenciamento da cadeia de distribuição. Rio de Janeiro: Campus, 2001. 
SOBRINHO, F. F.; COUTINHO, G. H.; COURA, J. D. Coleta de leite a granel, 1996. Monografia - Fundação João Pinheiro, Belo Horizonte, 1995.

YAMAGUCHI, L. C. T.; MARTINS, P. C.; CARNEIRO, A.
V. Produção de leite no Brasil nas três últimas décadas. In: GOMES, A. T.; LEITE, J. L. B.; CARNEIRO, A. V. (Ed.). O agronegócio do leite no Brasil. Juiz de Fora: Embrapa Gado de Leite, 2001, p. 33-48.

\section{DEVELOPMENT OF A LOGISTIC TOOL TO OPTIMIZE THE MILK SUPPLY OF AN AGRICULTURAL COOPERATIVE}

\section{Abstract}

This paper discusses the development and implementation of a model for optimizing the milk supply logistics of Cooperativa Agropecuaria Castrolanda, located in the state of Paraná, Brazil. The new logistics are being implemented in response to the restructuring of Brazil's dairy sector and the adoption of bulk milk collection and transportation. The model uses Clark and Wright's economy heuristic, which minimizes the total distance traveled, to represent transportation costs, subject to the constraints of each farm's production volume, tank capacity, and type of truck that can travel on main, secondary and farm roads. The main conclusions to be drawn from this study are the advantages the model offers over current empirical systems and imported commercial models which were originally developed to solve optimization problems in urban environments.

Keywords: dairy agribusiness, logistics, operational research. 